\title{
THE ROLE OF THE IRRITATIVE ZONE AND OF THE NUMBER AND DISTRIBUTION OF CALCIFICATIONS IN THE SEVERITY OF EPILEPSY ASSOCIATED WITH INTRACRANIAL CALCIFICATIONS
}

\author{
Pedro André Kowacs', Enio Rogacheski², Juliano Muzzio', Lineu César Werneck

\begin{abstract}
Objective: To determine the influence of the location of the irritative zone, and the number and the distribution of the intracranial calcifications in the severity of epilepsy associated with intracranial calcifications. Method: We studied 47 patients with epilepsy and intracranial calcifications, 24 with normal (Group A) and 23 with abnormal interictal EEGs (Group B), a control group $(n=21)$ with abnormal interictal EEGs and normal CT-scans (Group C). Clinical, electroencephalographic and neuroradiological featureswere compared among groups. Results: Temporal lobe interictal EEG abnormalities were found in 23/24 Group B patients, and in all Group C patients. Most Group B and Group C patients presented temporal lobe seizure symptomatology, whereas in most Group A patients symptomatology was rolandic $(p=0.0001)$. Epilepsy was more severe in Group B and Group C patients than in Group A patients ( $p=0.0001$ and $p=0.0054$ ). No relationship was found between the number of calcifications and epilepsy severity. Conclusion: An irritative zone at the temporal lobe is more relevant in determining the severity, symptomatology and frequency of seizures than the number and location of calcifications.
\end{abstract}

KEY WORDS: epilepsy-localized, epilepsy-temporal lobe, neurocysticercosis, cysticercosis, calcificationsintracranial.

\begin{abstract}
Papel da zona irritativa e do número e distribuição das calcificações na gravidade da epilepsia associada com calcificações intracerebrais

RESUMO - Objetivo: Testar a relevância do lobo temporal na epilepsia associada a neurocisticercose inativa. Método: Foram selecionados 47 pacientes com epilepsia e calcificações intracerebrais, 22 com EEGs intercríticos normais (Grupo A) e anormais em 23 (Grupo B) e um grupo controle $(n=21)$ com EEGs intercríticos anormais sem calcificações intracerebrais (Grupo C). Características clínicas, eletrencefalográficas e neuroradiológicas foram comparadas entre os grupos. Resultados: Encontramos anormalidades eletrencefalográficas temporais em 23/24 dos pacientes do Grupo B e em todos do Grupo C. Na maioria dos pacientes do Grupo B e Grupo C a sintomatologia ictal foi interpretada como temporal, porém no Grupo A como rolândica $(p=0,0001)$ A epilepsia foi mais grave nos grupos Grupo B e Grupo C que no Grupo A ( $p=0,0001$ e 0,0054). Não houve relação direta entre o número de calcificações e a gravidade da epilepsia. Conclusão: Uma zona irritativa sobre o lobo temporal é mais relevante na gravidade, sintomas e freqüência das crises que o número e a localização das calcificações.
\end{abstract}

PALAVRAS-CHAVE: epilepsia localizada, epilepsia do lobo temporal, neurocisticerose, cisticercose, calcificações intracerebrais.

As in other Latin American countries, neurocysticercosis has been identified in Brazil as the single main abnormality found on ancillary investigation of adults with epilepsy in primary health care services, university hospitals, and radiological clinic surveys $^{1-4}$. Although some studies have been carried out with the aim of determining the prognostic factors of epilepsy related to neurocysticercosis ${ }^{5-7}$, it has recently been shown that, in many cases, parenchymal neurocystice rosis leaves no clue for later diagnosis ${ }^{8}$. However, in these countries, calcified lesions a re the most common clinical presentation of neurocysticercosis associated with epileptic seizures ${ }^{1,3,9-11}$, occurring in $70-90 \%$ of patients with neurocysticercosis and epilepsy.

In a recent review of cysticercosis and epilepsy,

${ }^{1}$ Neurology and ${ }^{2}$ Radiology Division of the Internal Medicine Department, Hospital de Clínicas, Universidade Federal do Paraná, Curitiba PR, Brazil.

Received 30 June 2005, received in final form 26 June 2006. Accepted 31 July 2006.

Dr. Pedro André Kowacs - Serviço de Neurologia, Departamento de Clínica Médica - Hospital de Clínicas da Universidade Federal do Paraná - Rua General Carneiro 181 / $12^{\circ}$ andar / sala 1236 - 80060-900 Curitiba PR - Brasil. E-mail: pak@cwb.palm.com.br 
Carpio et al. ${ }^{12}$ pointed to the lack of studies with patients with acute symptomatic seizures, chronic recurrent seizures and newly diagnosed recurrent seizures.

We have carried out this study in an attempt to clarify the factors related to the severity of epilepsy associated with intracranial calcifications.

\section{METHOD}

Files for two sets of patients were selected from the patients' database at the HC-UFPR Hospital, in Curitiba, so u th e rn Brazil. One of the files i ncluded all the patients with intracranial calcifications and epilepsy that had attended the general neurology out-patient clinic during 1993. Inclusion criteria were age between 15 and 65 years, presence of calcifications on computerized tomography (CTscan) images of the brain and follow-up of one year. Exclusion criteria were presence of idiopathic or symptomatic generalized epilepsy ${ }^{13}$, presence of active systemic or neurological disease, seizures related to specific conditions and presence of severe mental retardation. All of the patients selected were interviewed by one of the investigators (PAK), and submitted to an inventory, according to the protocol. Of the 51 patients selected serially, four dropped out for the following reasons: mental retardation $(n=2)$; intracranial neoplasm $(n=1)$; and lack of will to participate $(n=1)$. Patients with intracerebral calcifications and a normal ro utine EEG were submitted to another tracing after 24 hours of sleep deprivation and subdivided into two groups - the $G$ roup $A$ (absence of an interictal EEG focus), and $G$ roup $B$ (presence of an interictal EEG focus). A control group (Group C) of patients with normal CT-scan images but abnormal EEGs was selected from the same out-patient clinic $(n=15)$ and from the epilepsy out-patient clinic $(n=6)(T a-$ ble 1).

Although the proportion of females was higher in both groups with abnormal EEGs compared with that of the Group A, the diffe rences were not statistically significant (Tables 2, 3 and 4). Only one patient from the Group B had been treated for neurocysticercosis with albendazole. Sei-

Table 1. Main criteria for the Groups A, B and C.

\begin{tabular}{llll}
\hline & Group A & Group B & Group C \\
\hline CT-scan & calcifications & calcifications & normal \\
Inter-ictal EEGs* & normal & focal spiking & focal spiking \\
\hline
\end{tabular}

* for patients with a normal interictal EEG a second EEG tracing after sleep deprivation was done.

Table 2. Demographics of Group A, Group B and C patients.

\begin{tabular}{|c|c|c|c|c|}
\hline \multicolumn{5}{|c|}{ Group A } \\
\hline & $\mathrm{n}$ & Mean \pm sd & Range & Median \\
\hline Males/Females & $13 / 11$ & & & \\
\hline Age & 24 & $28.5 \pm 11.0$ & $17-56$ & 25.5 \\
\hline Age* at first seizure & 24 & $13.3 \pm 10.8$ & $0.4-44$ & 12 \\
\hline Years of epilepsy & 24 & $15.2 \pm 10.8$ & $1-48$ & 13 \\
\hline Years in rural areas & 19 & $16.3 \pm 9.6$ & $2-36$ & 14 \\
\hline \multicolumn{5}{|c|}{ Group B } \\
\hline & $\mathrm{n}$ & Mean \pm sd & Range & Median \\
\hline Males/Females & $7 / 16$ & & & \\
\hline Age & 23 & $30.2 \pm 9.2$ & $15-52$ & 29 \\
\hline Age* $^{*}$ at first seizure & 23 & $9.3 \pm 7.6$ & $0.7-25$ & 7 \\
\hline Years of epilepsy & 23 & $20.9 \pm 8.6$ & $3-35$ & 22.5 \\
\hline Years in rural areas & 18 & $16.6 \pm 11.4$ & $0.6-41$ & 17.5 \\
\hline \multicolumn{5}{|c|}{ Group C } \\
\hline & $\mathrm{n}$ & Mean \pm sd & Range & Median \\
\hline Males/Females & $7 / 14$ & & & \\
\hline Age & 21 & $33.5 \pm 10.1$ & $21-55$ & 30 \\
\hline Age* $^{*}$ at first seizure & 21 & $11.7 \pm 10.3$ & $0.1-38$ & 10 \\
\hline Years of epilepsy & 21 & $21.8 \pm 9.1$ & $5-42$ & 23 \\
\hline Years in rural areas & 11 & $23.5 \pm 16.4$ & $1-51$ & 24 \\
\hline
\end{tabular}

Group A: intracranial calcifications and no interictal EEG abnormalities, Group B: intracranial calcifications with interictal EEG abnormalities, Group C: no intracranial calcifications but with interictal EEG abnormalities; * age in years; n: number. 
Table 3. Initial ictal symptomatology.

\begin{tabular}{|c|c|c|c|c|}
\hline \multirow[b]{2}{*}{$\begin{array}{l}\text { Initial ictal } \\
\text { symptoms }\end{array}$} & \multicolumn{4}{|c|}{ Groups } \\
\hline & $\begin{array}{c}\text { Group A } \\
n=24\end{array}$ & $\begin{array}{c}\text { Group B } \\
n=21^{*}\end{array}$ & $\begin{array}{c}\text { Group C } \\
n=19^{*}\end{array}$ & $\begin{array}{c}\text { Group B + Group C } \\
n=40^{*}\end{array}$ \\
\hline Rolandic & $11^{\#}$ & & 1 & 1 \\
\hline Temporal lobe & 6 & $14^{\#}$ & $15^{\#}$ & 29 \\
\hline Mixed & 5 & 7 & 2 & 9 \\
\hline Others & 2 & & 1 & 1 \\
\hline
\end{tabular}

zures were classified according to the 1981 ILAE revised proposal ${ }^{14}$. Seizure frequency was classified according to the last year of follow-up as no seizures, few seizures (less than one seizure a month), frequent seizures (at least one seizure a month) and very frequent seizures (one seizure or more a week). Severity of epilepsy was classified by combining average seizure frequency with seizure type (minor $=$ p a rtial ; major $=$ secondarily generalized) and classified as controlled, for no seizures in the last year, or as mild, moderate and severe, according to modified Pazzaglia criteria $^{15}$.

CT-scans of the head were performed with a $10^{\circ}$ angle. Ten millimeter and $6 \mathrm{~mm}$ intervals were used for imaging above and below the tentorium, respectively. Images were transposed to sketches of the tomograms by a board-certified neuroradiologist. Quantity of calcifications was classified as isolated $(n=1)$, sparse $(1<n \leq 5)$, and diffuse $(n>5)$, in accordance with the nomenclature used by the associated radiologist (ER). For Group B patients, location of calcifications was compared to location of surface EEG foci. Calcifications of the patients in each group were superimposed in a single sketch, and the Group A sketch was compared with the Group B sketch.
Table 4. Group B and Group C interictal EEG abnormalities.

\begin{tabular}{lccc}
\hline & $\begin{array}{c}\text { Group B } \\
(n=23)\end{array}$ & $\begin{array}{c}\text { Group C } \\
(n=21)\end{array}$ & $\begin{array}{c}\text { Total } \\
(n=44)\end{array}$ \\
\hline Location / Abnormalities & & & \\
Temporal lobe foci* & 23 & 21 & 44 \\
$\quad$ Unilateral & 17 & 16 & 33 \\
$\quad$ sharp waves and spikes & 6 & 5 & 11 \\
$\quad$ slow waves & 7 & 5 & 12 \\
Bilateral & 4 & 4 & 8 \\
$\quad$ sharp waves and spikes & 3 & 1 & 4 \\
$\quad$ slow waves & 1 & & \\
Extratemporal foci & 1 & & 2 \\
$\quad$ sharp waves and spikes & 1 & & 1 \\
$\quad$ slow waves & 1 & 1 & 2 \\
Lateralized abnormalities & & & 1 \\
$\quad$ sharp waves and spikes & 1 & & \\
slow waves & & & \\
\hline
\end{tabular}

n, number; *temporal lobe foci with or without associated extratemporal foci; note: some patients presented more than a single EEG abnormality.

Table 5. Severity of epilepsy in Group A, Group B and Group C patients.

\begin{tabular}{lcccc}
\hline & Group A & Group B & Group C & Total \\
\hline Controlled & 10 & 2 & 3 & 15 \\
Mild & 6 & 2 & 4 & 12 \\
Subtotal & 16 & $4^{\#}$ & 7 & 27 \\
Moderate & 5 & 4 & 5 & 14 \\
Severe & 3 & $15^{\ddagger}$ & $9^{\#}$ & 27 \\
Subtotal & 8 & 19 & 14 & 41 \\
Total & 24 & 23 & 21 & 68 \\
\hline
\end{tabular}

\#: $p<0.005 ;: p<0.0001$. 


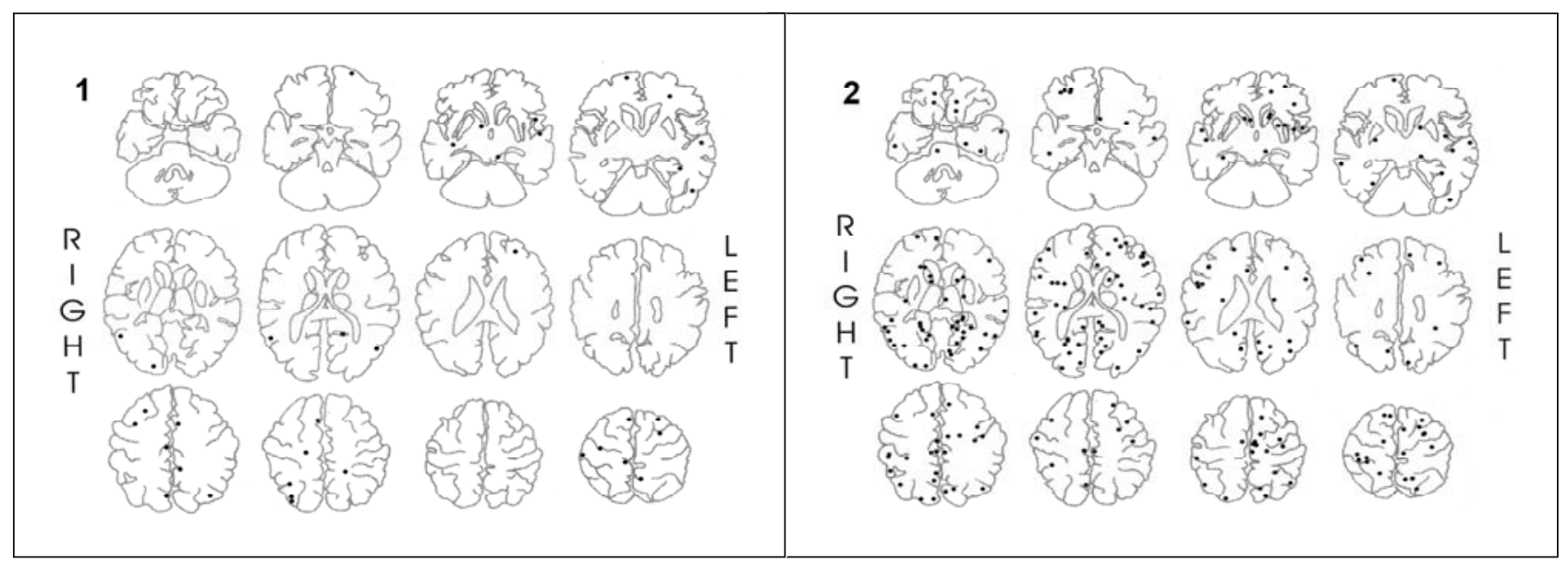

Figs 1 and 2. Distribution of all intracranial calcifications transposed to sketches of the CT-scan images of Group A patients (upper figure) and Group B patients (lower figure). The sketches of the brain were adapted from Berman SA et al, AJR Am J Roentgenol $1980 ; 135: 253-257$.

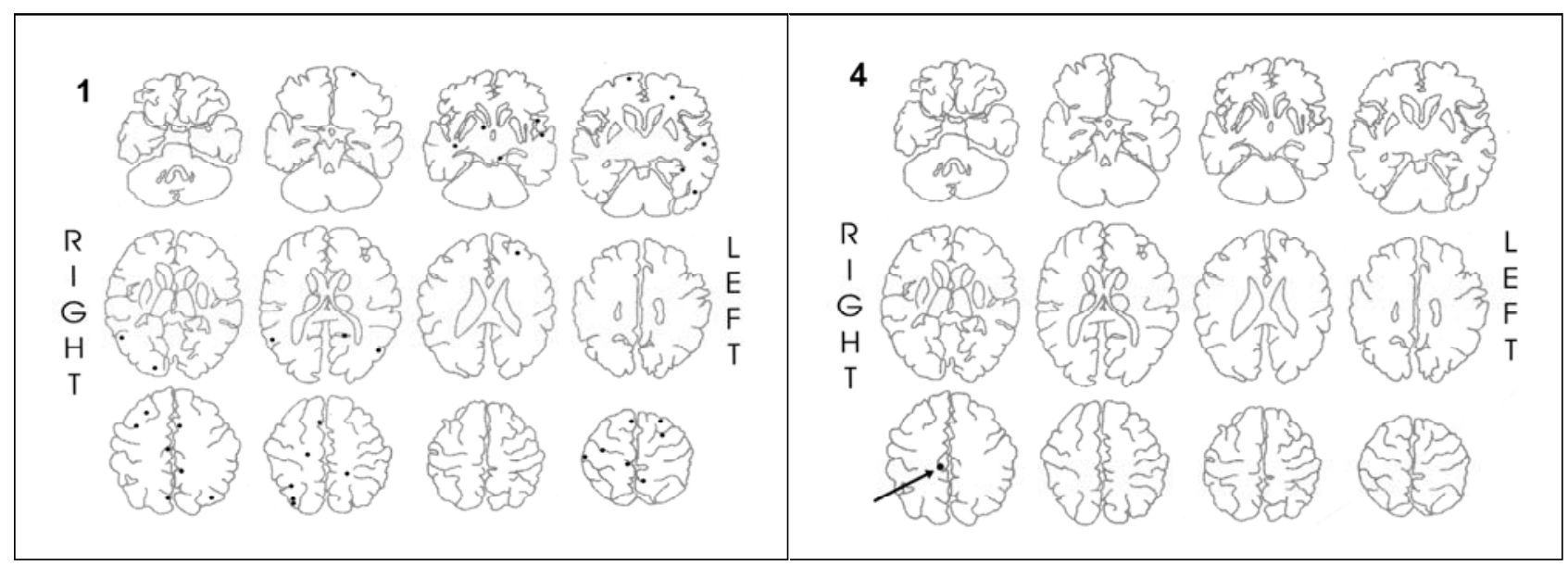

Figs 3 and 4. Examples of patients without a relationship between the localization and number of intracranial calcifications and the type and severity of epilepsy. Upper sketches: diffuse intracranial calcifications and mild right rolandic epilepsy. Lower sketch es: single right parietal intracranial calcification and severe left temporal lobe epilepsy. The interictal EEG of this patient disclosed left temporal spiking. The sketches of the brain were adapted from Berman SA et al, AJR Am J Roentgenol 1980;135:253-257.

The possible relationship between the number of calcifications and severity of epilepsy was studied. The level of significance was determined by the Qui-square test corrected by Yates and by Fisher's exact test.

The publication of the study was approved by the local regulatory institution.

\section{RESULTS}

In the Group A, patients without seizures in the last year prior to the study or with infrequent (low frequency) secondarily generalized seizures were more common than patients with frequent or very frequent (high frequency) secondarily generalized seizures $(p<0.005)$. No difference, however, was found between high frequency or low frequency simple and complex partial epileptic seizures in the same group.
In the Group B, patients with frequent or very frequent simple and complex partial seizures predominated over those without seizures or with infrequent seizures $(p=0.001)$ in the last year prior to the study.

In the Group C, no difference was found in seizure $f$ requency between partial and secondarily generalized seizures.

F requent or very frequent partial seizures were more common among Group B patients than Group A patients $(p<0.05)$. Group B patients and Group C patients re p o rted frequent or very frequent secondarily generalized seizures significantly more often than Group A patients $(p<0.05)$.

When only the partial symptoms of seizures were analyzed, those symptoms suggestive of temporal 
lobe seizures were re $\mathrm{p}$ o rted more frequently by the Group B patients and Group C patients, while rolandic seizure symptomatology was more frequently described by Group A patients ( $p=0.0001$, Table 3 ). No diffe rence was found when the location of EEG foci were compared between Group B and Group C. Most of the electroencephalographic abnormalities occurred over the temporal lobe in both groups (Table 4).

Average number of calcifications was higher for the Group A (mean=12.1) than for the Group B (mean $=9.8$ ). Figures 1 and 2 respectively show all the intracranial calcifications for the Group A and Group $B$ patients transposed from their original CT-scan images to sketches of the brain, with one set of sketches for each group. There was no difference between the two groups in terms of the number of cases in which isolated, sparse or diffuse calcifications were found. With regard to severity of epilepsy, when controlled and mild epilepsy were compared against moderate and severe epilepsy within the three groups, $G$ roup $B$ patients presented a significantly more severe epilepsy than Group A patients $(p<0.005)$. When controlled, mild and moderate epilepsy were compared to severe epilepsy, the diffe rence between the Group A and the Group B increased, and in the Group $C$, epilepsy was found to be significantly more severe than in the Group A ( $p=0.0001$ and 0.005 , respectively). No difference was found between severity of epilepsy in Group B and Group C patients.

The data regarding severity of epilepsy can be appreciated in Table 5. When the number of calcifications was plotted against severity of epilepsy taking Group A and Group B together, there was an inverse relationship between the number of calcifications and severity of epilepsy. Figures 3 and 4 show examples of disparities between the number of calcifications and severity of epilepsy.

\section{DISCUSSION}

Neurocysticercosis is the main cause of adult-onset seizures in the developing world ${ }^{16-23}$. Calcified cysticerci have been reported as the most common finding in tomograms of epileptic patients in Brazil, probably because Brazil includes a number of underdeveloped areas ${ }^{17-20}$.

Nonetheless, an association between the number of lesions that became calcified and the persistence of seizures has been described ${ }^{5-7}$. In these studies, however, follow-ups were carried out after therapy for cysticercosis, and the use of steroids during cysticidal therapy might have changed the natural history of the disorder.
F rom anecdotal reports, collected series, and previous observations in patients with seizures, perilesional edema related to calcifications appears to be relatively frequent, ranging from $23 \%$ to about $35 \%$ in patients with calcified neurocysticercosis and a histo ry of seizures ${ }^{24}$. When present, these areas of perilesional seizure - related transient edema are thought to represent the epileptogenic zone. Indeed, seizures may be a late manifestation of neurocysticercosis even after adequate treatment, because cicatricial tissue remains as a permanent sequela ${ }^{25,26}$. Two retrospective studies published in 1992 found striking diff erences in the evolution of seizures in favor of antiparasitic treatment ${ }^{6,27}$, but in 1995 a controlled trial showed no diffe rences among patients treated with albendazole, praziquantel or corticosterads alone ${ }^{28}$. In Brazil, however, the majority of patients diagnosed as having round intracranial calcifications on CT-scan images and epilepsy had never been submitted to therapy with praziquantel or albendazo $\left.\right|^{2,9,29}$. In these patients, cysticerci usually degenerated spontaneously. We could not find a direct relationship between the number of calcifications and the severity of epilepsy in our patients, but the inverse relationship between the number of calcifications and more severe epilepsy, although significant, might have been biased by Group B patients, who also had active interictal foci. Studies suggest a lack of a relationship between the burden of the neurocysticercotic lesions and the severity of the epilepsy. Some patients with severerefractoryepilepsy have only one calcified lesion; by contrast, other patients have many cysts or calcifications but no epilepsy. Local inflammation and immunity studies in the brain point to significant differences in both disorders in the different areas of the brain, thus adding other sources of local variation in the host-parasite relationship ${ }^{26}$. Because of the high prevalence of epilepsy and neurocysticercosis in less developed countries, there could be a causal as well as fortuitous relationship between the two disorders ${ }^{30,31}$.

The presence of interictal epileptiform activity on EEG tracings was associated with a more severe epilepsy, since there was no diff e rence between Gro up $B$ and Group C in terms of severity of epilepsy, but in both groups epilepsy was more severe than in the Group A. In some studies, active interictal epileptiform activity has been found to be associated with a worse prognosis ${ }^{32}$, and in others this was true for a b n o rmalities recorded over the frontal and temporal lobes ${ }^{33}$. Previous studies of epilepsy and neurocysticercosis have not shown a relationship between 
interictal EEG abnormalities and severity or pro g n osis of epilepsy associated with neurocysticercosis, but most of them included both patients with acute symptomatic seizures and those with unprovoked seizures due to remote symptomatic epilepsy. Although our study was not designed to evaluate prognosis, its results suggest that careful EEG investigation should be performed in these patients, since interictal abnormalities over the temporal lobes may have prognostic significance.

Interpreting the pathophysiology of epilepsy associated with intracranial calcifications as secondary to increased firing of the neurons around the lesion is an oversimplification. This becomes evident in cases presenting a mismatch between the location of the calcifications and the EEG foci or the seizure symptoms. Indeed, Benabis and Lüders stated that the syn$d$ romic approach to epilepsy had been underuse $d^{34}$. Another study noted that $18 \%$ of patients studied presented complex partial seizures, and reported that EEG abnormalities were associated with simple and complex partial seizures ${ }^{35}$. In most of the studies, however, little attention was paid to a syndromic approach. Bittencourt et al analyzed 24 patients with epilepsy and neuro cy s t i ce rcosis and compared them with 17 patients with temporal lobe epilepsy alone. They concluded that there was no significant difference in the rates of co-localization of the presumptive epileptogenic foci between the patients with temporal lobe epilepsy and those with neurocysticer$\operatorname{cosis}^{36}$.

The coexistence of hippocampal atrophy and extrahippocampal pathologic abnormalities is referred to in the literature as "dual pathology" and has been reported in 5 to $30 \%$ of patients with medically refractorypartial seizures ${ }^{37,38}$. More recently, the association between neurocysticercosis and mesial temporal lobe epilepsy has been reported in anecdotal form in the literature ${ }^{39,40}$, but in a larger series the neuropathologic findings indicated that patients with hippocampal sclerosis and calcified cysticercosis have a pattern of hippocampal cell loss and an amount of fascia dentate mossy fiber reorganization indistinguishable from classic cases of hippocampal sclerosis ${ }^{41}$.

Some new perspectives on the subject have already been investigated in Brazil. In a brief communication, Martinez et al. re p o rted 11 cases of epilepsy surgery on patients with intracranial calcifications, with mesial temporal sclerosis being described in some ${ }^{42}$. More recently, Jorge et al. compared the clinical presentation and surgical outcome of patients with mesial temporal sclerosis with and without associated intracranial calcifications, and found no significant differences between the two groups. These finding were confirmed by Leite et al. who also discovered that the pathologic findings at the hippocampus were similar for the two groups, and concluded that the presence of calcified lesions did not influence the profile of patients with hippocampal atrophy, and that these patients responded to temporal lobectomy as well as the patients without intracranial calcifications ${ }^{43}$. The aforementioned works support the view that we should not be bound to the old concepts of calcification=epileptogenic lesion and/or focus, but rather search for other markers of severity in refractorycases of epilepsy and intracranial calcifications, such as the syndromic presentation, the interictal EEG findings and MRI imaging. Finally, we would like to emphasize a view that is now acceptable, namely that the presence of intracranial calcifications on CT-scan images of the brain should not be a criterion for excluding patients from epilepsy surgery protocols.

Acknowledgements - The authors express their thanks to Dr. Duilton de Paola and Dr. Mara Balliana for EEG interpretation, and to Dr. Carlos Silvado for his suggestions.

\section{REFERENCES}

1. Medina MT, Rosas E, Rubio-Donnadieu F, Sotelo J. Neurocysticercosis as the main cause of late-onset epilepsy in Mexico. Arch Intern Med 1990;150:325-327.

2. Arruda WO. Etiology of epilepsy: a prospective study of 210 cases. Arq Neuropsiquiatr 1991;49:251-254.

3. Teive HAG, Tsubouchi MH, Ferreira MVC, Minguetti M. Análise de 1000 tomografias computadorizadas do crânio em pacientes com crises epilépticas. Arq Neuropsiquiatr 1992;50:70.

4. Gracia AK. Avaliação preliminar de casos de neurocisticerese diagnosticada em um serviço de tomografia em Curitiba-PR nos anos de 1992 e 1993. In: Anais do I Encontro Cone Sul e Seminário LatinoAmericano sobre Teníase e Cisticercose, Curitiba, SESA: UFPR: OPAS: MS/FNS, 1994:180-181.

5. Medina MT, Cordova S, Genton P, Sotelo J, Dravet C, Montoya MC. $P$ rognosis in neurocysticerosis: the effect of anticysticercal treatment. Epilepsia 1991;32(Suppl 1):S110-S111.

6. Vasquez $\mathrm{v}$, Sotelo $\mathrm{j}$. The course of seizures after treatment for cerebral cysticercosis. N Engl J Med 1992;327:696-701.

7. Del Brutto, $\mathrm{OH}$. Prognostic factors for seizure recur rence after withdrawal of antiepileptic drugs in patients with neurocysticercosis. Neurology 1994;44:1706-1709.

8. Garcia HH, Gilman RH, Catacora M, Verastegui M, Gonzalez AE, Tsang VCW, and the Cysticercosis Working Group in Peru. Serologic evolution of neurocysticercosis patients after antiparasitic therapy. J Infect Dis 1997; 175:486-489.

9. Takayanagui OM. Neurocistice rcose evolução clínico-laboratorial de 151 casos. Arq Neuropsiquiatr 1990;48:1-10.

10. Palacio LG, Jiménez I, Garcia HH, et al. Neurocysticercosis in persons with epilepsy in Medellín, Colombia. Epilepsia 1998;39:1334-1339.

11. Carpio A. Hauser WA. Neurocysticercosis and epilepsy. In: Singh G, Prabhakar S (eds). Taenia solium cysticercosis. Wallingford, UK: CABI Publishing, 2002:211-220.

12. Carpio A, Escobar A, Hauser WA. Cysticercosis and epilepsy: a critical review. Epilepsia 1998;39:1025-1040. 
13. Commission on Classification and Terminology of the International League Against Epilepsy. Proposal for revised classification of epilepsies and epileptic syndromes. Epilepsia 1989;30:389-399.

14. Commission on Classification and Terminology of the International League Against Epilepsy. Proposal for revised clinical and electroencephalographic classification of epileptic seizures. Epilepsia 1981;22:489-501.

15. Pazzaglia P, D' Allessandro R, Lozito A, Lugaresi E. Classification of partial epilepsies according to the symptomatology of seizures: practical value and prognostic implications. Epilepsia 1982;23:343-350.

16. Garcia HH, Pretell J, Gilman RH, et al. A trial of antiparasitic treatment to reduce the rate of seizures due to cerebral cysticercosis. N Engl J Med 2004;350:249-258.

17. Narata AP, Arruda WO, Uemura E, et al. Neurocisticercose: diagnóstico tomográfico em pacientes neurológicos. A rq Neuropsiquiatr 1998;56:245-249.

18. Arruda WO, Camargo NJ, Coelho RC. Neurocysticercosis: an epidemiological survey in two small rural communities. A rq Neuropsiquiatr 1996;48:419-424.

19. Gonçalves Coelho TD, Coelho MDG. Cerebral Cysticercosis in Campina Grande, Paraíba - northern Brazil. Arq Neuropsiquiatr 1996;54:94-97.

20. Teive HAG, Minguetti G, Sasaki MGM, Lopes CER, Carvalho MTM, Szpeiter N. Neurocisticercose. Rev Bras Neurol 1997;33:147-153.

21. Riley T, White AC Jr. Management of neurocysticercosis. CNS Drugs 2003;17:577-591.

22. Sotelo J. Neurocysticercosis. In Aminoff MJ, Daro ff RB (eds). Encyclopedia of the neurological sciences. San Diego, Calif.: Academic Press, 2003:474-475

23. Proaño JV, Madrazo I, Avelar F, López-Felix B, Díaz G, Grijalva I. Medical treatment for neurocysticercosis characterized by giant subarachnoid cysts. N Engl J Med 2001;345:879-885.

24. Fleury A, Dessein A, Preux PM, et al. Symptomatic human neurocystice roosis: age, sex and exposure factors relating with disease heterogeneity. J Neurol 2004. 251:830-837

25. Pradhan S, Kathuria MK, Gupta RK. Perilesional gliosis and seizure outcome: a study based on magnetization transfer magnetic resonance imaging is patients with neurocysticercosis. Ann Neurol 2000:48:181-187.

26. Nash TE, Del Brutto OH, Butman JA, et al. Calcific neurocysticercosis and epileptogenesis. Neurology 2004;62:1934-1938.

27. Del Brutto OH, Santibanez R, Noboa CA, A g u i r re R, Diaz E, Alarcon TA. Epilepsy due to neurocysticercosis: analysis of 203 patients. Neurology 1992;42:389-392.

28. Carpio A, Santillan F, Leon P, Flores C, Hauser WA. Is the course of neurocysticerosis modified by treatment with antihelminthic agents? Arch Intern Med 1995;155:1982-1988.
29. Quagliato EMAB. Forma epiléptica da cisticercose encefálica, análise de 96 casos. Tese. Campinas, 1987

30. Bromfield EB, Vonsattel J-P. Weekly Clinicopathological Exercises: Case 24-2000: A 23-year-old man with seizures and a lesion in the left temporal lobe. N Engl J Med 2000; 343:420-427.

31. Sakamoto AC, Bustamante VCT, Garzón E, et al. Cysticercosis and epilepsy. In Kotagal P, Luders HO (eds). The epilepsies: etiologies and prevention. San Diego: Academic Press, 1999:275-282.

32. Rodin EA. Various prognostic aspects in patients with epilepsy. Folia Psychiatr Neurol Jpn 1978;32:407-418.

33. The Group for the Study of Prognosis of Epilepsy in Japan. Natural history and prognosis of epilepsy: report of a multi-institutional study in Japan. Epilepsia 1981;22:35-53.

34. Benbadis SR, Lüders HO. Epileptic syndromes: an underutilized concept. Epilepsia 1996;37:1029-1034.

35. MonteiroL, Nunes B, Mendonça D, Lopes J. Spectrum of epilepsy in neurocysticercosis: a long-term follow-up of 143 patients. Acta Neurol Scand 1995;92:33-40

36. Goldsmith P, Sandmann MC, Souza DS, Mazer S, Antoniuk A, Bittencourt PRM. The relationship between parasite location and electroclinical abnormality in neurocysticercosis. Neurol Infect Epidemiol 1996; 1:127-133.

37. Cendes F, Cook MJ, Watson C, et al. Frequency and characteristics of dual pathology in patients with lesional epilepsy. Neurology 1995; 45:2058-2064.

38. Raymond AA, Fish DR Stevens JM, Cook MJ, Sisodiya SM, Shorvon SD. Association of hippocampal sclerosis with cortical dysgenesis in patients with epilepsy. Neurology 1994;44:1841-1845.

39. Chung CK, Lee SK, Chi JG. Temporal lobe epilepsy caused by intrahippocampal calcified cysticercus: a case report. J Korean Med Sci 1998; 13:445-448.

40. Garg RK, Karak B, Mohan Kar A. Neuroimaging abnormalities in Indian patients with uncontrolled partial seizures. Seizure 1998;7:497-500.

41. Leite JP, Terra-Bustamante VC, Fernandez RMF, Santos AC, Chimelli L, Sakamoto AC, Assirati JA, Takayanagui OM. Calcified neurocysticercotic lesions and postsurgery seizure control in temporal lobe epilepsy. Neurology 2000;55:1485-1491.

42. Martinez JAG, Cukiert A, Marino R Jr, Yacubian EM. Cirurgia de epilepsia em pacientes com calcificações neurocisticercóticas. Braz J Epilep Clin Neurophysiol 1995;1:131.

43. Jorge CL, Valério RMF, Bueno JF, Guilhoto LMFF, Valente KDR, Yacubian EMT. Mesial temporal sclerosis: related or not to neurocysticercosis. Arq Neuropsiquiatr 1998;58 (Suppl 1):S205. 